\title{
Paradigm Shifts in Language Acquisition and its Application in the Present Scenario
}

\author{
Swayam Prabha Satpathy \\ Associate Professor in Communication. Siksha "O"Anusandhan University. \\ Department of Humanities \& Social Sciences, Khandagiri, Bhubaneswar, Odisha 751030, India
}

\section{ARTICLE INFO}

Article history

RECEIVED: $12-$ Sep-19

REVISED: 02-NoV-19

ACCEPTED: 04-Dec-19

PUBLISHED: 16-Dec-19

*Corresponding Author:

Email: dr.swayam.prava@gmail.com

\begin{abstract}
Language is both the 'medium' and the 'manner' of education. It enables the process of teaching and learning to take place; and one of the principal goals of education is the development of students' ability to use language. Learning in all subjects involves comprehensibility of the use of language adapted to develop particular areas of knowledge and expertise. The focus is mainly concerned with spoken language. It is examined interaction between teachers and learners and interaction amongst learners. But before focusing on talk in educational settings, it is imperative on our part to consider the use and functions of language, and its relationship to a student's thinking, in a more general way.
\end{abstract}

Keywords: Comprehensibility, Education, Interaction, Language.

\section{Introduction}

A socio-cultural perspective on language and learning reflects a particular view of how language and social interaction are involved in the processes of development and learning. With this viewpoint of perspective, education and cognitive development are seen as cultural processes, whereby knowledge is not only possessed individually but shared amongst members of communities; and understandings are built by people jointly, through their involvement in events which are shaped by cultural and historical factors. Language acquisition and use is seen as having a profound effect on the development of thinking. The development of the thought process to some extent depends on the language acquired. But some view that we cannot understand the nature of thinking, learning, and development without taking account of the intrinsically social and communicative nature of humans.

\section{Meaning of 'discourse'?}

Hicks (1995) points to the importance of the notion of discourse in recent socio-cultural context. Discourse is a key factor in contemporary work in the social sciences and its meaning varies according to the particular theorists that researchers draw on. For example, in applied linguistics research, discourse is often used to refer to a stretch of language - spoken or written - in context (Crystal, 1997). In contrast, for many social theorists, notably post-structuralist social philosophers such as Foucault (1980), discourse refers to socially and historically situated domains of knowledge or ways of construing the world. In the first reading, Hicks emphasises the work of researchers on language who aim to combine the more concrete use of discourse as actual stretches of language with some elements of the more abstract notion of discourse from social theory.

1. Discourse as 'language in its social context, as it is used to carry out the social and intellectual life of a community' (Mercer, 1995, p. 79). This meaning of discourse emphasizes the importance of looking at language in context and usually involves an analysis of actual stretches of spoken and written language, often referred to as 'texts'.

2. Discourse as 'different ways of structuring areas of knowledge and social practice' (Fairclough, 1992, p. 
3). This is a more abstract meaning of the term than

(1) as it is not used to refer to particular texts, but rather to explain how certain ideas and values are embodied in the communications of a community or society. Discourse in this sense cannot be observed or recorded but is rather a theory of social reality.

3. While we can differentiate these two kinds of meaning of the term 'discourse', it is important to understand that it is often used in ambiguous ways. The focus primarily is on actual instances of language in context: interaction in the classroom. But the second meaning is also briefly referred to; for example by linking actual instances of talk in classrooms with college as a particular kind of institution with its own particular language values and beliefs. The importance of the notion of discourse in what are known as social constructionist perspectives on language, including a socio-cultural perspective, is that language not only reflects but constructs social reality. As Hicks points out in her reading, classroom life is constituted through the specific discourse practices in which students and teachers engage.

\section{Interaction in educational Institutes}

Schools and Colleges are special kinds of places, social Institutions with particular purposes, cultures and traditions. So, although teaching and learning takes place in many other places outside the formal education system, the language pattern differs as well as the language use. The patterns of language use are generated, though this may not be well recognized by teachers because they are focused on driving out the apprehensions of the language, and because they take these features for granted. Even students whose mother tongue is the language they use in school have much to learn about how that language is used as an educational medium.

The most obvious kind of spoken language used in education is between teachers and learners. There is a lot of interaction that takes place between teachers and students. If we analyze the teacher's perspectives of making the language comprehensible, it has important effects on how their students use the language. One of the most obvious functions of spoken language in a classroom for teachers is to tell students what they are to do, how they are to do it, when to start and when to stop. The essential paraphernalia to teach the students while using the language is the impact that they create while speaking. Interactive classroom is the means by which teachers can provide students with information, a lot of which would be very hard to communicate in any other way. Language in most educational contexts is also the main tool for a teacher's control of events in the classroom apart from being a help to students to bridge the gap between language acquisition and its application.

\section{Language and identity}

Language has long been seen as closely connected with identity in a number of distinctive ways. Traditionally, the language people speak has been connected with their national identity: English, Spanish, Japanese, and so on. Within any one language there are different language varieties which are also connected with particular identities. In India we have a plurality of languages which undoubtedly shows unity in diversity but at the same time it becomes difficult to communicate with the wider world. Hence the pedagogical approach to language application is intervened. Teachers as well as students make an effort to learn a language which has global acceptance and which creates self-identity.

Socio-linguists have studied differences of accent and communicative style in the language of people of different age groups and generations, in order to find out how languages shift and change over the course of time, and in men and women's use of language, which has been seen as reflecting gender specific practices and relationships.

Hence, in order to bring in a global identity where all can interact in one common language the medium of instruction is English.

It is also recognized that children and adults from different social groups bring different kinds of language resources into the classroom and that these influence their identity as a student. Particular uses of language and literacy are highly valued in the classroom and seen as important for learning, and there has been considerable argument about how far the language of children and adults from various ethnic and class communities is different or deficient in relation to competencies required in educational settings (Labov, 1972; Michaels, 1981; Heath, 1983; Tizard and Hughes, 1984).

These amalgamations of language use and group identity (class, gender, generation, ethnicity) remain significant, but a number of important paradigm shifts in the ways in which social scientists recognize the role of language in relation to other aspects of social life have had some profound implications for issues of language and identity. The theoretical shift in ways of looking at identity is part 
of a more general acknowledgement within the social sciences of the importance of the dynamic processes of social life and the role of language within these. For instance, there has been an increasing interest in the way in which people use language collaboratively to accomplish intellectual as well as practical tasks. As we stressed in section 1, language is both the medium and the message of education. This more social constructionist approach sees knowledge not so much as a body of facts and information but rather as the outcome of particular kinds of social interactions and processes. It has also been applied to understanding other aspects of social life. So, for instance, social categories like class, gender or ethnicity are increasingly seen not as intrinsic labels of identity residing within the individual, but as experienced by people as a more or less salient aspect of who they are through their experience in different interactions and dialogues, across different contexts.

According to Mercer (1995) context can be defined in terms of the resources invoked by speakers to make sense of a particular communicative exchange. These resources may include:

- The surroundings

- The past shared experience and relationship of the speakers

- The speakers' shared tasks and goals

- The speakers' experience of similar kinds of conversation.

\section{Language variety, style and identity}

The idea that individual and group identity is constantly being negotiated and renegotiated through changes of everyday social interactions has been explored by many. There were differences, too, in the language styles (pitch, pronunciation, and grammar) used. The major challenge among students is the different 'communication styles, each involving students who have come together to share ways of doing things and ways of talking, beliefs and values, as a function of their shared engagement in the activity. Individual identity is constructed in collaboration with others in and around this communication of practice.

\section{English as a second language and identity}

Learners of English as a second language (ESL), especially the ones who do not use it often, have found that the identity positions offered them within the English speaking community can be crucial for their development of fluency in the language. In a study of the experience of the students who come from various communities with their own acquired language find difficulties in mastering English cannot be adequately explained by traditional second language acquisition theory. This would explain their progress as the result of their individual motivation, self-confidence and communication anxiety and the degree to which they were prepared to assimilate the lifestyle and values of society and thus maximize their contact with their peer groups and the possibilities for natural language use.

When we look at the students who tend to be interested in learning the second language, they are not free from communicative apprehensions and feel learning English is much more problematic than this suggests. It happens that the students develop a disinterest as they lack fluency in English and because of their current lack of fluency their negativity towards the language is developed. They get into their own cocoons and rarely open up. This self marginalization limits their opportunities to practice English and also reduced their confidence and heightened their anxiety so that they felt reluctant to initiate conversations with other workers.

Norton (2000) argues that confidence and anxiety are not individual attributes, but are socially constructed encounters between the second language learners and the majority community, and that these encounters are structured by relations of inequality. Similarly, class and ethnicity do not reside in the individual, but are constructed and realized through social relations.

These kinds of communication apprehensions make the students devoid of participation. Hence there are certain pedagogical approaches to language learning which are adopted although Pennycook (1998) suggests inequalities between communities and second language learners are also deeply encoded within the discourse of ESL teaching and within the textbooks used with learners. He traces the teaching of English as a second language back to its historical roots in nineteenth century British colonialism and assumptions about the inherent superiority of the English language and, by association, of native English speakers.

\section{Research focus}

As discussed in this section, there are different ways of conceptualizing the relationship between language use 
and adapting the language to create an identity, and these are evident in different approaches.

The pedagogical approach to language learning has been more student centric and efforts are being taken to take the interests of the learning the language. With the advent of the mobile phones students are keener to work with mobiles. So mobile assisted learning can be an approach to teach them a language which they are apprehensive about.

VaiRamanathan (1999) focuses on the powerful status of English. She draws on the work of Kachru (1985), who argues that there is a deep-seated unequal power relationship on a global level between an inner circle of English speakers (comprised of Britain and its former old colonies the United States, Canada, and Australia) and an outer circle comprised of formerly colonial English speaking countries in Asia and Africa. Practice at this level is not 'observable' in any straightforward way. It may be possible to 'implement various teaching strategies so that the students come out of their communication apprehensions and are more convinced to learn and apply the language.

\section{Summary and Conclusion}

The beginning of this section suggested that the shift toward paradigm shifts and ideas within the field of language studies, as well as more generally within the social sciences, has opened up new opportunities for examining and understanding some of the complex relationships between identity, or, subjectivity, and the importance of teaching and learning. This shift has involved the development of a new conceptual apparatus for analyzing social processes and the role of language within these. The ways in which students take on other people's voices in their talk and writing is seen as significant both for their learning and for their developing awareness of themselves as particular kinds of people. In addition to re-emphasizing specific language applications, students tend to apply the vocabulary and discursive structures of a particular language, aligning themselves with particular ideological positions as well as producing written assignments. In pedagogic terms, it becomes essential on the part of teachers to educate the students to apply Language; ethnic and other social differences can still, however, create powerful barriers for individual students, and relationships of inequality and exclusion are deeply embedded in situational practices and social values. Research shows how people's experience of language and identity has been affected by wide-ranging and substantive global changes.

We concluded this section by focusing on ways of researching and analyzing the relationship between language use, and identity. In particular, it is to be focused on the way in which the notion of practice can be researched upon the shifts in teaching learning process.

\section{References}

Crystal, D. (1997). A Dictionary of Linguistics and Phonetics, Oxford, UK: Basil Blackwell

Fairclough, N. (1992). Discourse and Social Change, (pp. 3). Cambridge, Polity Press

Foucault, M. (1980). Power/Knowledge: selected interviews and other writings 1972-1977, (pp. 3334). Brighton, London: Harvester

Heath, S. B. (1983). Ways with Words: language, life and work in communities and classrooms, (pp. 1214). Cambridge, London: Cambridge University Press

Hicks, D. (1995). Discourse, Learning, and Teaching. Review of Research in Education, 21, 4995.

Kachru, B. B. (1985). 'Standards, codification, and sociolinguistic realism: the English language in the outer circle'. In R. Quirk \& H. Widdowson (Eds.), English in the World: teaching and learning the language and literatures, (pp. 1113). Cambridge, London:Cambridge University Press

Labov, W. (1972). Language in the Inner City, Philadelphia, US: University of Philadelphia Press

Mercer, N. (1995). The Guided Construction of Knowledge: talk amongst teachers and learners, (pp. 79). Clevedon, UK: Multilingual Matters

Michaels, S. (1981). 'Sharing time: children's narrative styles and differential access to literacy', Language in Society, $10,423-42$

Norton, B. (2000). Identity and Language Learning: gender, ethnicity and educational change, (pp.57).London, UK: Longman

Pennycook, A. (1998). . English and the Discourses of Colonialism, Abingdon, UK:Routlege.

Ramanathan, V. (1999). 'English is here to stay: a critical look at institutional and educational practices in India', TESOL Quarterly, Vol.33, No.2, Summer 1999. Copyright (C1999 Teachers of English to Speakers of Other Languages, Inc.

Tizard, B. and Hughes, M. (1984) .Young Children Learning: talking and thinking at home and at school, (pp 57). London, (UK): Fontana 